\title{
Evaluation of Nitrilotrimethylene Phosphonic Acid and Nitrilotriacetic Acid as Corrosion Inhibitors of Mild Steel in Sea Water
}

\author{
P. K. Kar ${ }^{1}$ and Gurmeet Singh ${ }^{2}$ \\ ${ }^{1}$ Department of Chemistry, VSS University of Technology, Burla, Orissa 768018, India \\ ${ }^{2}$ Department of Chemistry, University of Delhi, Delhi 110007, India
}

Correspondence should be addressed to P. K. Kar, pravinkar@yahoo.com

Received 12 June 2011; Accepted 7 July 2011

Academic Editors: F. Cabrera-Escribano and K. Kusabiraki

Copyright ( $) 2011$ P. K. Kar and G. Singh. This is an open access article distributed under the Creative Commons Attribution License, which permits unrestricted use, distribution, and reproduction in any medium, provided the original work is properly cited.

\begin{abstract}
The inhibition efficiency of nitrilotrimethylene phosphonic acid (NTP) in controlling mild steel corrosion in sea water has been evaluated by galvanostatic polarization, electron scanning for chemical analysis (ESCA), and scanning electron microscope (SEM) methods. The results are compared with those obtained for nitrilotriacetic acid (NTA). NTP is found to be more effective in protecting mild steel against sea water corrosion as compared to NTA. The surface of mild steel in presence and absence of NTP and NTA is characterized by ESCA and SEM. From the ESCA studies, it is found that NTP formed a stable and compact film over the mild steel.
\end{abstract}

\section{Introduction}

Sea water is a complex natural electrolyte. The corrosion is severe due to the presence of chloride ions and dissolved oxygen. Sea water has been used as cooling fluid in various industries. So, it is imperative to study the corrosion aspect and find out suitable corrosion inhibitors to be used in sea water. Phosphonic acids are extensively used nowadays due to their complex forming abilities. They are also widely used due to their low toxicity, high stability, and high-scale inhibition properties [1-7]. Mild steel is used extensively for its technological properties. The present study aims to (i) find out the corrosion inhibition effects of phosphonic acid groups on mild steel in sea water medium by using nitrilotrimethylene phosphonic acid (NTP) and compare the results with those for nitrilotriacetic acid (NTA), (ii) study the nature of the film on the mild steel surface by using ESCA and SEM, and (iii) propose a mechanism of the corrosion inhibition for the inhibitors in sea water.

\section{Experimental}

Specimen. Mild steel $(\mathrm{C}=0.15 \%, \mathrm{Mn}=1.02 \%, \mathrm{Si}=0.085, \mathrm{~S}=$ $0.025 \%$, and $\mathrm{P}=0.025 \%$ ) of $2 \mathrm{~mm}$ thickness was used. The specimen was cut in to $1 \mathrm{~cm} \times 1 \mathrm{~cm}$ for galvanostatic studies and $0.5 \mathrm{~cm} \times 0.5 \mathrm{~cm}$ for ESCA and SEM studies. Each mild steel specimen was carefully coated with epoxy resin leaving one $\mathrm{cm}^{2}$ flat surface uncoated. The exposed surface was polished with emery papers of 150, 320, 400, and 600 grades and finally with $4 / 0$ polishing paper. The surface cleaning was done in ultrasonic cleaner Ralsonic model R-30/40 using deionised water.

For galvanostatic studies, potentials were measured with the help of digital potentiometer against saturated calomel electrode with platinum electrode as counter electrode. The open circuit potential was achieved in 6 hours.

X-ray photoelectron Spectroscope ESCA-750, Shimadzu, was used. It was operated at $5 \times 10^{-9}$ torr with $\mathrm{Mg}_{\mathrm{K} \alpha} \mathrm{X}$-ray radiation (1253.6 eV). SEM studies were done with JEOL840 SEM operated at $10 \mathrm{KV}$ in the secondary electron mode.

Chemicals. Nitrilotriacetic acid (NTA), Sigma-Aldrich, USA, was used. NTP was synthesized from NTA. Natural aerated sea water with salinity of $36.1 \mathrm{ppt}$ was used.

\section{Results and Discussion}

3.1. Galvanostatic Polarisation. Figure 1 shows the typical polarization curves for mild steel in sea water in the presence of NTP and NTA. The corrosion current densities $\left(I_{\text {corr }}\right), E_{\text {corr }}$ 


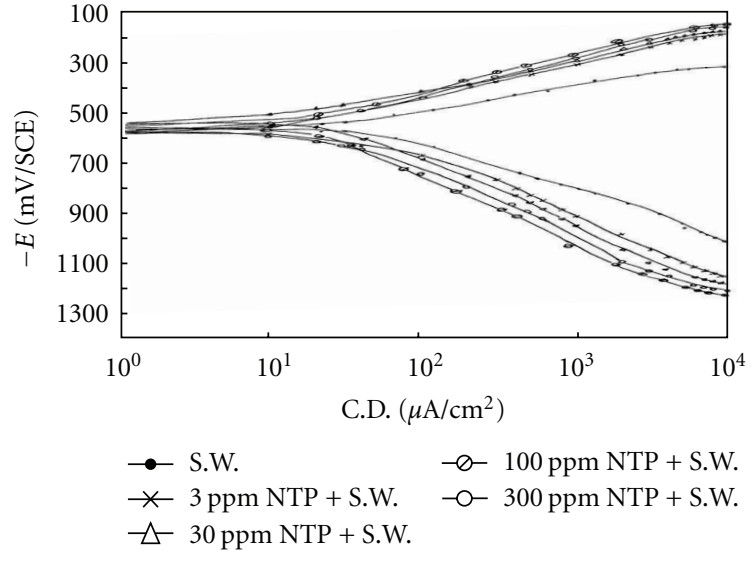

(a)

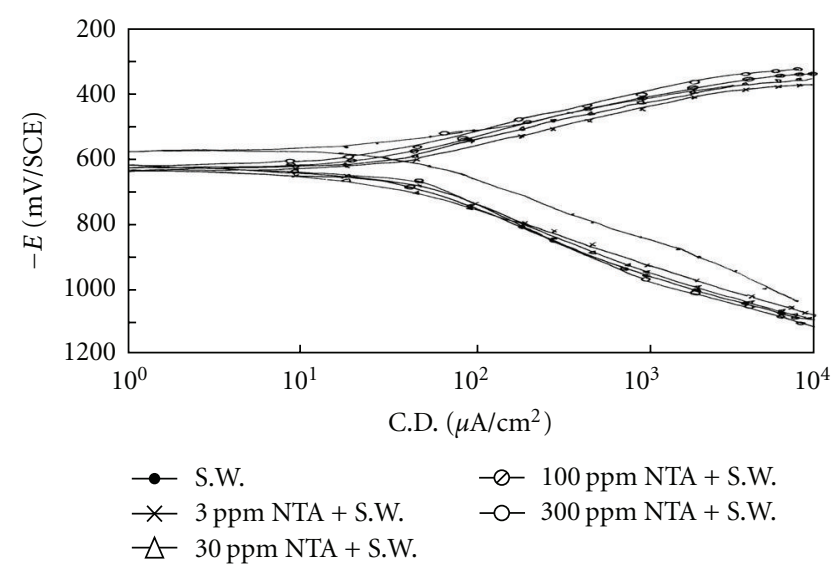

(b)

Figure 1: Galvanostatic polarization curves for mild steel in sea water in presence of different concentrations of (a) NTP and (b) NTA.

and Tafel slope values are calculated and are given in Table 1. Corrosion current is found to the presence of both NTP and NTA although the effect is more pronounced in the presence of NTP. Therefore, NTP inhibits the corrosion of mild steel in sea water media better than NTA. The lower inhibition efficiency of NTA may be attributed to lesser adsorption and to greater solubility of corrosion products [8]. The inhibition efficiency increases with increase in concentration of NTP till $100 \mathrm{ppm}$ and then decreases. This may be due to dissolution of the oxide outer layer. The inhibitor efficiency of NTA is found to increase with concentration.

The values of Tafel slopes $\left(b_{c}>b_{a}\right)$ in sea water suggest the predominance of oxygen reduction reaction as predictedv by Deslouis et al. [9]. The presence of NTP and NTA increases and decreases $b_{c}$, respectively, whereas $b_{a}$ almost is unaffected in both the cases.

The presence of NTP does not produce any significant change in the $E_{\text {corr }}$ value whereas the presence of NTA shifts the $E_{\text {corr }}$ value in the cathodic direction. Therefore, NTP is a mixed type of inhibitor and suppresses both anodic and cathodic partial processes whereas NTA mainly acts by suppressing the cathodic partial processes.

Marcus and Herbelin [10] have proposed that an exchange takes place between $\mathrm{Cl}^{-}$and $\mathrm{OH}^{-}$ions in the passive layer in chloride environment. Several modes of inhibition in solution containing chloride ions have been suggested [11, 12] including blocking of adsorbed $\mathrm{Cl}^{-}$ions by competitive adsorption. NTP might be inhibiting by formation of [Fe$\mathrm{OH}-\mathrm{NTP}]_{\mathrm{ad}}$ and $[\mathrm{Fe}-\mathrm{OH}-\mathrm{Cl}-\mathrm{NTP}]_{\mathrm{ad}}$ film over iron surface.

The inhibition efficiency of NTA is lower than that of NTP molecules. NTA molecules are adsorbed over the metal surface by (i) $\mathrm{p}-\mathrm{d}$ interaction and (ii) ion pair adsorption between iron and NTA molecules. The adsorbed layers block the penetration of chloride ions onto the metal surface. The lower inhibition efficiency can be attributed to lower adsorption of NTA molecules as compared to NTP molecules. The lower efficiency may also be attributed to greater solubility of corrosion products [8].

3.2. ESCA Studies. Binding energies of various elements are reported in Table 2 .

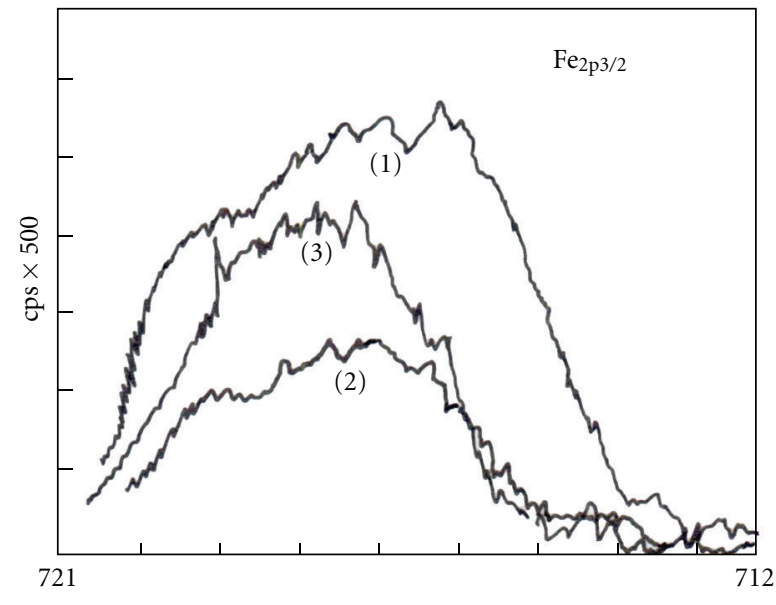

$(\mathrm{eV})$

Figure 2: XPS spectra of iron $\left(\mathrm{Fe}_{2 \mathrm{p} 3 / 2}\right)$ (1) in sea water, (2) in presence of $300 \mathrm{ppm}$ of NTP, and (3) in presence of $300 \mathrm{ppm}$ of NTA.

More of oxygen and less chloride are present on the surface in case of mild steel sample in sea water. Two peaks of $\mathrm{O}_{1 \mathrm{~S}}$ indicate presence of both oxide and hydroxide. The $\mathrm{Fe}_{2 \mathrm{P} 3 / 2}$ peak at $717.3 \mathrm{eV}$ (Table 2) suggests existence of $\mathrm{Fe}^{+2}$ and $\mathrm{Fe}^{+3}$ in the film $[1,7,13-16]$ (Figure 2(1)). The presence of $\mathrm{Cl}_{2 \mathrm{P} 3 / 2}$ at $204.3 \mathrm{eV}$ indicates chloride adsorption over the metal surface (Figure 3(1)). It is clear from the depth profile that the amount of iron increased and that of oxygen decreased during successive etchings.

A broad peak at $717.6 \mathrm{eV}$ indicates the presence of $\mathrm{Fe}^{+2}$ and $\mathrm{Fe}^{+3}$ on the surface of mild steel in $300 \mathrm{ppm}$ of NTPv (Figure 2(2)). Two peaks are observed for $\mathrm{Cl}_{2 \mathrm{p}}(197.7 \mathrm{eV}$ and $205.4 \mathrm{eV}$ ) (Figure 3(2)) and $\mathrm{P}_{2 \mathrm{p}}(139.1 \mathrm{eV}$ and $130.6 \mathrm{eV}$ ) (Figure 4). One peak is observed for $\mathrm{C}_{1 \mathrm{~s}}(290.4 \mathrm{eV})$ and one for $\mathrm{N}_{1 \mathrm{~s}}(405.7 \mathrm{eV}$ ) (Figure 5(1)) in presence of $300 \mathrm{ppm}$ NTP (Table 2). The presence of these elements indicted the film formed to be a thick one [3]. Two peaks of $\mathrm{O}_{1 \mathrm{~s}}$ indicate presence of both oxide and hydroxide (Figure 6(a)).This 
TABLE 1: Corrosion parameters of mild steel in sea water in presence of inhibitors at $298 \mathrm{~K}$.

\begin{tabular}{lccccc}
\hline Concentration $(\mathrm{ppm})$ & $-E_{\text {corr }}(\mathrm{mV})$ & $I_{\text {corr }}\left(\mu \mathrm{A} / \mathrm{cm}^{2}\right)$ & $b_{c}(\mathrm{mV} / \mathrm{dec})$ & $b_{a}(\mathrm{mV} / \mathrm{dec})$ & Inhibition efficiency $(I \%)$ \\
\hline 0 & 564 & 53.0 & 255 & 145 & 74.5 \\
3 NTP & 590 & 13.5 & 320 & 125 & 79.2 \\
30 NTP & 555 & 11.0 & 315 & 125 & 87.7 \\
100 NTP & 550 & 6.5 & 310 & 125 & 84.9 \\
300 NTP & 585 & 8.0 & 305 & 135 & 39.6 \\
3 NTA & 644 & 32.0 & 180 & 115 & 45.3 \\
30 NTA & 638 & 29.0 & 180 & 115 & 49.1 \\
100 NTA & 630 & 27.0 & 180 & 125 & 51.9 \\
300 NTA & 625 & 25.5 & & \\
\hline
\end{tabular}

TABLE 2: Binding energies $(\mathrm{eV})$ of elements present on mild steel surface after and before treatment with inhibitors.

\begin{tabular}{lcccccrrr}
\hline Solution & Fe 2 $\mathrm{p}_{3 / 2}$ & $\begin{array}{c}\mathrm{O} 1 \mathrm{~S} \\
\mathrm{O}\end{array}$ & $\begin{array}{c}\mathrm{O} 1 \mathrm{~S} \\
\mathrm{OH}\end{array}$ & $\mathrm{Cl} 2 \mathrm{p}_{1 / 2}$ & $\mathrm{Cl} 2 \mathrm{p}_{3 / 2}$ & P 2p & C 1S & N 1S \\
\hline Sea water & 717.3 & - & 537.5 & - & 204.3 & - & - \\
3 ppm NTP & 718.2 & 536.7 & 537.6 & 197.6 & 203.7 & 140.0 & 289.5 & 407.2 \\
300 ppm NTP & 717.6 & 536.2 & 537.4 & 197.7 & 205.4 & 139.1 & 290.4 & 405.7 \\
3 ppm NTA & 717.9 & 536.1 & 537.4 & 196.5 & 204.4 & - & 289.7 & 405.5 \\
300 ppm NTA & 717.1 & 536.1 & 537.2 & 196.5 & 205.3 & - & 290.3 & 405.9 \\
\hline
\end{tabular}

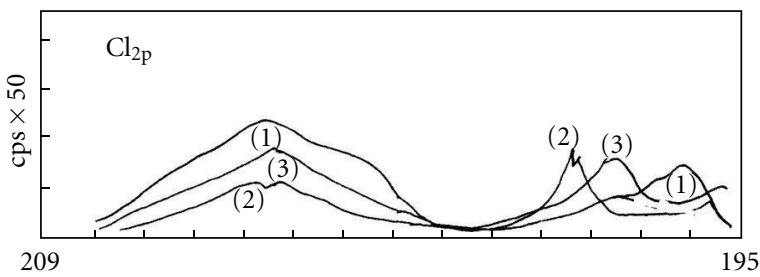

$(\mathrm{eV})$

FIGURE 3: XPS spectra of $\mathrm{Cl}_{2 \mathrm{p}}$ (1) in sea water, (2) in presence of $300 \mathrm{ppm}$ of NTP and (3) in presence of $300 \mathrm{ppm}$ of NTA.

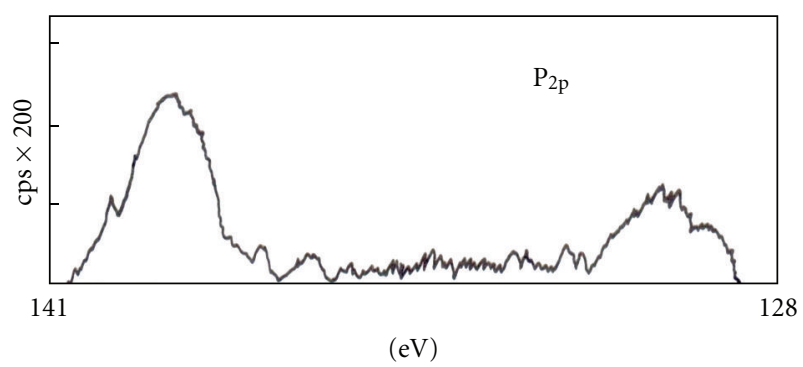

FIGURE 4: XPS spectra of $\mathrm{P}_{2 \mathrm{p}}$ in presence of $300 \mathrm{ppm}$ of NTP.

indicates the presence of $\mathrm{FeO}$ and $\mathrm{FeOOH}$ [17]. A peak at $205.4 \mathrm{eV}$ of $\mathrm{Cl}_{2 \mathrm{p}}$ indicates adsorbed $\mathrm{Cl}^{-}$over the metal surface. The other peak at $197.7 \mathrm{eV}$ indicates formation of complex $[\mathrm{Fe}-\mathrm{OH}-\mathrm{Cl}-\mathrm{NTP}]_{\mathrm{ad}}$ with the inhibitor molecule on the metal surface. These peaks for $\mathrm{Cl}_{2 \mathrm{p}}$ spectrum indicate certain amount of $\mathrm{Cl}^{-}$inclusion in the passive film consisting of iron oxide hydroxide. The amount of $\mathrm{O}$ and $\mathrm{Cl}^{-}$present over mild steel indicated that after a first stage of adsorption, an

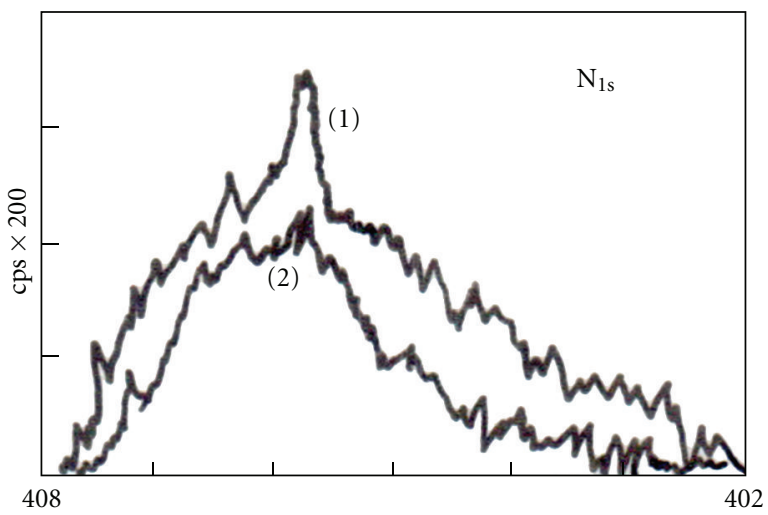

$(\mathrm{eV})$

Figure 5: XPS spectra of $\mathrm{N}_{1 \mathrm{~s}}$ (1) in presence of $300 \mathrm{ppm}$ of NTP and (2) in presence of $300 \mathrm{ppm}$ of NTA.

oxide-hydroxide-chloride layer is formed. Rossi et al. [4] have suggested that chloride ions are repelled by $\mathrm{PO}_{3}{ }^{3-}$ away from the metal surface. This decreased the adsorption of chlorides leading to higher resistance against localized corrosion. Phosphorus showed two $\mathrm{P}_{2 \mathrm{p}}$ peaks at $139.1 \mathrm{eV}$ and $130.6 \mathrm{eV}$. The $\mathrm{P}_{2 \mathrm{p}}$ peak at $139.1 \mathrm{eV}$ is shifted from the characteristic elemental binding energy of $130.0 \mathrm{eV}$ for $\mathrm{P} 2 \mathrm{p}_{3 / 2}$ and $131.0 \mathrm{eV}$ for $\mathrm{P} 2 \mathrm{p}_{1 / 2}$ [18]. It can be attributed to presence of phosphorus from NTP in the surface film over the metal sur-face leading to uniform coverage. The other peak at $130.1 \mathrm{eV}$ is due to formation of metal phosphorus adduct over the mild steel. The change in binding energy implies decrease in electron cloud over $\mathrm{P}-\mathrm{O}$ and shift towards iron surface. One peak for $\mathrm{N} 1 \mathrm{~s}$ is observed at $405.7 \mathrm{eV}$, which is shifted from 


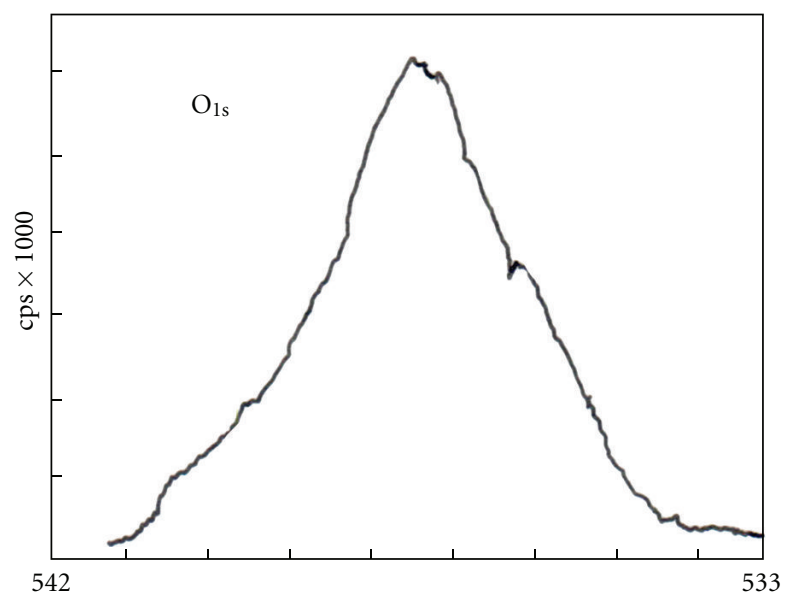

$(\mathrm{eV})$

(a)

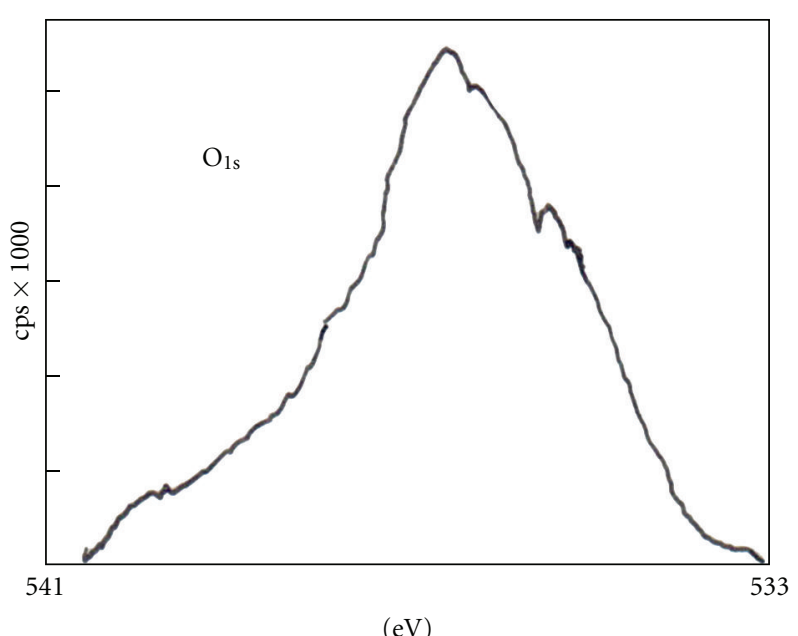

(b)

FIGURE 6: XPS spectra of $\mathrm{O}_{1 \mathrm{~s}}$ (a) in presence of $300 \mathrm{ppm}$ of NTP and (b) in presence of $300 \mathrm{ppm}$ of NTA.

characteristic value of $398.0 \mathrm{eV}$ [18]. This shift may be attributed to presence of NTP molecule in the surface film in the form of a complex with the metal [19]. For $3 \mathrm{ppm}$ of NTP, more amount of iron is found as compared to $300 \mathrm{ppm}$. Two peaks for $\mathrm{Cl}$ are observed with increasing amount at $203.7 \mathrm{eV}$ while that at $197.6 \mathrm{eV}$ almost remains the same as compared to $300 \mathrm{ppm}$ NTP suggesting complex formation with the inhibitor over the surface. Only one peak for $\mathrm{P}_{2 \mathrm{p}}$ is observed at $140 \mathrm{eV}$ indicating presence of NTP on the metal surface. The amount of phosphorus is less than that obtained for $300 \mathrm{ppm}$ NTP suggesting lesser adsorption.

In case of $300 \mathrm{ppm} \mathrm{NTA}$, the amount of iron found on the surface is quite high as compared to NTP (Figure 2(3)). There is little shift in binding energy of iron and oxygen indicating less compound formation. Two peaks of $\mathrm{Cl}^{-}$indicate formation of complex as well as adsorption over metal surface. The amount of $\mathrm{Cl}^{-}$at $196.5 \mathrm{eV}$ is less and that at $205.3 \mathrm{eV}$ is more than those obtained for NTP (Figure 3(3)). Only one peak for $\mathrm{N}_{1 \mathrm{~S}}$ is found at $405.9 \mathrm{eV}$, and the amount is less than that obtained for NTP indicating lesser adsorption of the inhibitor (Figure 5). Two peaks for O1s indicate the presence of both oxide and hydroxide of iron (Figure 6(b)). The presence of these elements suggests complex formation with the metal on the surface. The amounts of iron and chloride are higher, and those of $\mathrm{C}, \mathrm{N}, \mathrm{O}, \mathrm{Cl}(196.5 \mathrm{eV})$ are lower in case of $3 \mathrm{ppm}$ NTA as compared to $300 \mathrm{ppm}$ NTA suggesting very small surface coverage. The amount of iron present in this case can be compared to that for sea water.

These observations show decrease of electron cloud density of the $\mathrm{P}-\mathrm{O}$ bond due to shift of electron cloud density from $\mathrm{O}$ to $\mathrm{Fe}$ atom in case of phosphonic acid molecules [20]. These studies also reveal that NTP molecules are strongly adsorbed over mild steel surface even in presence of chloride ions. These observations confirm the formation of [Fe-OH$\mathrm{NTP}]_{\text {ad }}$ and $[\mathrm{Fe}-\mathrm{OH}-\mathrm{Cl}-\mathrm{NTP}]_{\text {ad }}$ film over mild steel surface in case of NTP and [Fe-OH-Cl-NTA] film over the mild steel surface in case of NTA. The formation of Fe-NTP complex is a kind of ternary surface complex composed of metal ions, NTP, and solid precipitates of ferric hydroxide or ferric oxide on the surface of mild steel. This makes the film compact, steady, and complete, which resists mass transport and retards permeation of corrosion products through the film. The lower inhibition efficiency in case of NTA can be attributed to noncompactness of the $[\mathrm{Fe}-\mathrm{OH}-\mathrm{Cl}-\mathrm{NTA}]_{\mathrm{ad}},[\mathrm{Fe}-\mathrm{OH}-$ $\mathrm{NTA}]_{\mathrm{ad}}$ layers formed over the mild steel surface.

3.3. Scanning Electron Micrographs. The surface micrographs of mild steel treated with sea water with and without inhibitors are shown in Figure 7. It can be seen from Figure 7(a) that severe corrosion takes place in case of mild steel treated with sea water only and there is formation of corrosion prod-ucts on the surface. Corrosion is less in case of mild steel treated with sea water in presence of $300 \mathrm{ppm}$ of NTP (Figure 7(b)). In case of mild steel treated with sea water in presence of $300 \mathrm{ppm}$ NTA, as shown in Figure 7(c), seems to be more corroded than $300 \mathrm{ppm}$ of NTP but less than that with only sea water. It can be inferred that the surface film formed by inhibitors exhibits good protection for mild steel.

The following mechanism can be proposed for inhibition of corrosion of mild steel in chloride medium in presence of these inhibitors:

$$
\begin{aligned}
& \mathrm{M}+\mathrm{Cl}^{-} \longrightarrow\left[{\mathrm{M}-\mathrm{Cl}^{-}}_{\mathrm{ad}}\right. \\
& {\left[\mathrm{M}-\mathrm{Cl}^{-}\right]_{\mathrm{ad}}+\mathrm{H}_{2} \mathrm{O}+\mathrm{NTP} / \mathrm{NTA}} \\
& \longrightarrow[\mathrm{M}-\mathrm{OH}-\mathrm{NTP} / \mathrm{NTA}]_{\mathrm{ad}}+\mathrm{Cl}^{-}+\mathrm{H}^{+} \\
& {\left[{\mathrm{M}-\mathrm{Cl}^{-}}_{\mathrm{ad}}+\mathrm{H}_{2} \mathrm{O} \longrightarrow\left[\mathrm{M}-\mathrm{OH}-\mathrm{Cl}^{-}\right]_{\mathrm{ad}}\right.} \\
& {\left[\mathrm{M}-\mathrm{Cl}^{-}\right]_{\mathrm{ad}}+\mathrm{H}_{2} \mathrm{O} \longrightarrow[\mathrm{M}-\mathrm{OH}]_{\mathrm{ad}}+\mathrm{Cl}^{-}+\mathrm{H}^{+}} \\
& {\left[\mathrm{M}-\mathrm{Cl}^{-}\right]_{\mathrm{ad}}+\mathrm{H}_{2} \mathrm{O}+\mathrm{NTP} / \mathrm{NTA}} \\
& \longrightarrow\left[\mathrm{M}-\mathrm{OH}-\mathrm{Cl}^{-} \mathrm{NTP} / \mathrm{NTA}\right]_{\mathrm{ad}}
\end{aligned}
$$




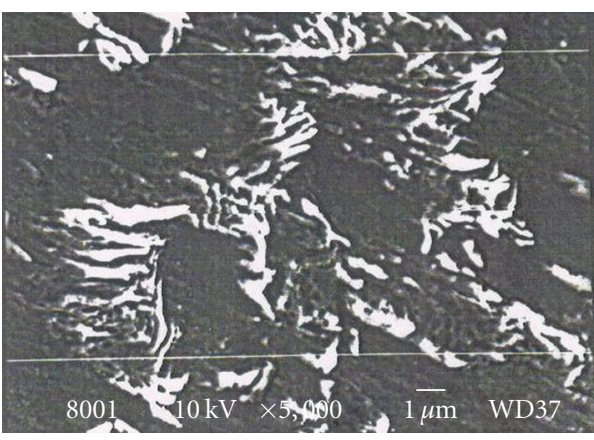

(a)

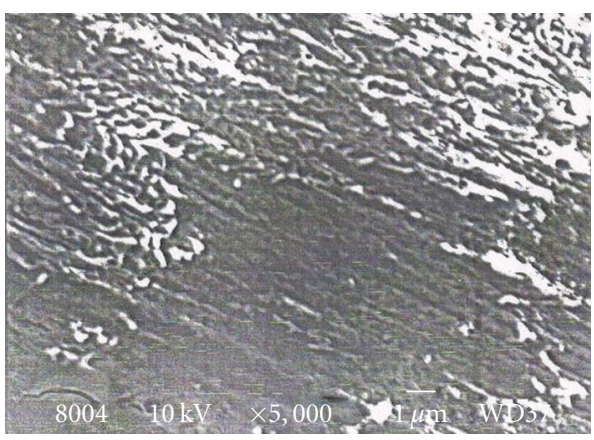

(b)

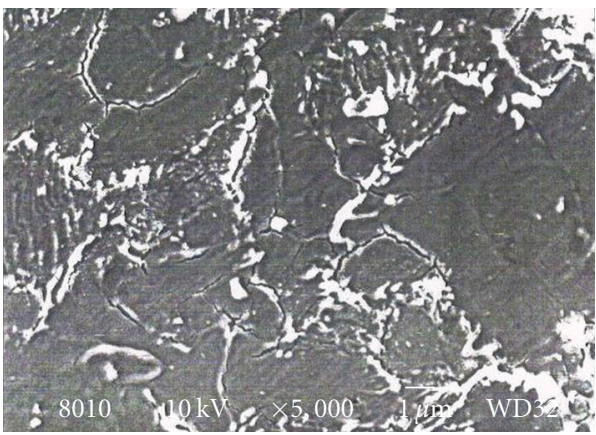

(c)

Figure 7: SEM of mild steel in (a) sea water, (b) sea water in the presence of $300 \mathrm{ppm}$ of NTP, and (c) sea water in the presence of $300 \mathrm{ppm}$ of NTA.

\section{Conclusions}

(i) Both NTP and NTA inhibit corrosion of mild steel in sea water, although the NTP performs better than NTA.

(ii) Inhibition efficiency increases with increase in concentration of NTP till $100 \mathrm{ppm}$, and then it decreases whereas the inhibition efficiency increases with increase in concentration of NTA.

(iii) NTP is a mixed type of inhibitor whereas NTA is cathodic type of inhibitor.

(iv) NTP shows higher inhibition efficiency against corrosion of mild steel in sea water than NTA because it forms stable $[\mathrm{Fe}-\mathrm{OH}-\mathrm{NTP}]_{\mathrm{ad}}$ and $[\mathrm{Fe}-\mathrm{OH}-\mathrm{Cl}-$ $\mathrm{NTP}]_{\text {ad }}$ complexes over the metal surfaces.

(v) The results of SEM are in correlation with the results of electrochemical and ESCA studies.

\section{References}

[1] S. Virtanen, E. M. Moser, and H. Böhni, "XPS studies on passive films on amorphous Fe-Cr-(B,P)-C alloys," Corrosion Science, vol. 36, no. 2, pp. 373-384, 1994.

[2] E. Kalman, "Inhibitors of low toxicity for aqueous solutions," in Proceedings of the 7th European Symposium on Correosion Inhibitors (7SEIC), p. 745, Ann univ. (ferrara), 1990.

[3] J. L. Fang, Y. Li, X. R. Ye, Z. W. Wang, and Q. Liu, "Passive films and corrosion protection due to phosphonic acid inhibitors," Corrosion, vol. 49, pp. 266-272, 1993.

[4] A. Rossi, D. De Filippo, S. Virtanen, and B. Elsener, in Proceedings of the 11th International Congress On Corrosion, vol. 3, p. 539, Italy, 1990.

[5] E. Kalman, B. Varhegyi, I. Bako, I. Felhosi, F. H. Karman, and A. Shaban, "Corrosion inhibition by 1-hydroxy-ethane1,1-diphosphonic acid. An electrochemical impedance spectroscopy study," Journal of the Electrochemical Society, vol. 141, no. 12, pp. 3357-3360, 1994.

[6] T. Horvath and E. Kalman, "Study of corrosion inhibition phenomena in acidic media by electrochemical and surface analysis techniques," Russian Journal of Electrochemistry, vol. 36, no. 10, pp. 1085-1091, 2000.

[7] N. Ochoa, G. Basil, F. Moran, and N. Pébère, "Study of the properties of multi component inhibitor used for water treatment in cooling circuits," Journal of Applied Electrochemistry, vol. 32, no. 5, pp. 497-504, 2002.

[8] E. Heitze, "Fundamentals of the corrosion of metals in organic solvents-1," Werkstoffe und Korrosion, vol. 21, no. 5, pp. 360367,1970

[9] C. Deslouis, M. C. Lafont, N. Pébère, and D. You, "Corrosion inhibition of pure iron in neutral solutions by electrochemical techniques," Corrosion Science, vol. 34, no. 10, pp. 1567-1579, 1993.

[10] P. Marcus and J. M. Herbelin, "The entry of chloride ions into passive films on nickel studied by spectroscopic (ESCA) and nuclear (36Cl radiotracer) methods," Corrosion Science, vol. 34, no. 7, pp. 1123-1145, 1993.

[11] M. Yamaguchi, H. Nishihara, and K. Aramaki, "The inhibition of passive film breakdown on iron in a borate buffer solution containing chloride ions by organic anion inhibitors," Corrosion Science, vol. 36, no. 2, pp. 241-258, 1994.

[12] J. G. N. Thomas, "Some new fundamental aspects in corrosion inhibition," Journal of Applied Physics, vol. 2, pp. 453-470, 1980.

[13] J. A. Bearden and A. F. Burr, "Reevaluation of X-ray atomic energy levels," Reviews of Modern Physics, vol. 39, no. 1, pp. 125-142, 1967.

[14] J. C. Fuggle and N. Martenssen, "Core-level binding energies in metals," Journal of Electron Spectroscopy and Related Phenomena, vol. 21, no. 3, pp. 275-281, 1980.

[15] A. Rossi, A. B. Elsener, and N. D. Spenser, "Spectroscopy Europe," pp. 14-19, www. Spectroscopyeurope.com.

[16] "NIST surface structure Database," www.nist.gov.

[17] T. M. Sridhar, K. S. K. Danadurai, and S. Rajeswari, "Electron spectroscopy for chemical analysis (ESCA) of passive films formed on type 316LN SS in pulp and paper industry," 
Transactions of the Indian Institute of Metals, vol. 57, no. 3, pp. 241-252, 2004.

[18] J. F. Moulder, P. E. Stickle, W. F. Sobol, and K. D. Bamben, Hand Book of X-Ray Photoelectron Spectroscopy, Physical Electronics, Eden Prairie, Minn, USA, 1995.

[19] B. V. A. Rao, M. V. Rao, S. S. Rao, and B. Shreedhar, "Tungstate as a synergist to phosphonate based formulation for corrosion control of carbon steel in nearly neutral aqueous environment," Journal of the Chemical Society, vol. 122, no. 4, pp. 639-649, 2010.

[20] S. Rajendran, B. R. Earnest John Peter, A. Peter Pascal Regis, A. John Amalraj, and M. Sundaravadivelu, "Influence of chloride ion concentration on the inhibition efficiency of the HEDPZn2+ system," Transactions of the Society for Advancement of Electrochemical Science and Technology, vol. 38, no. 1, pp. 1115, 2003. 

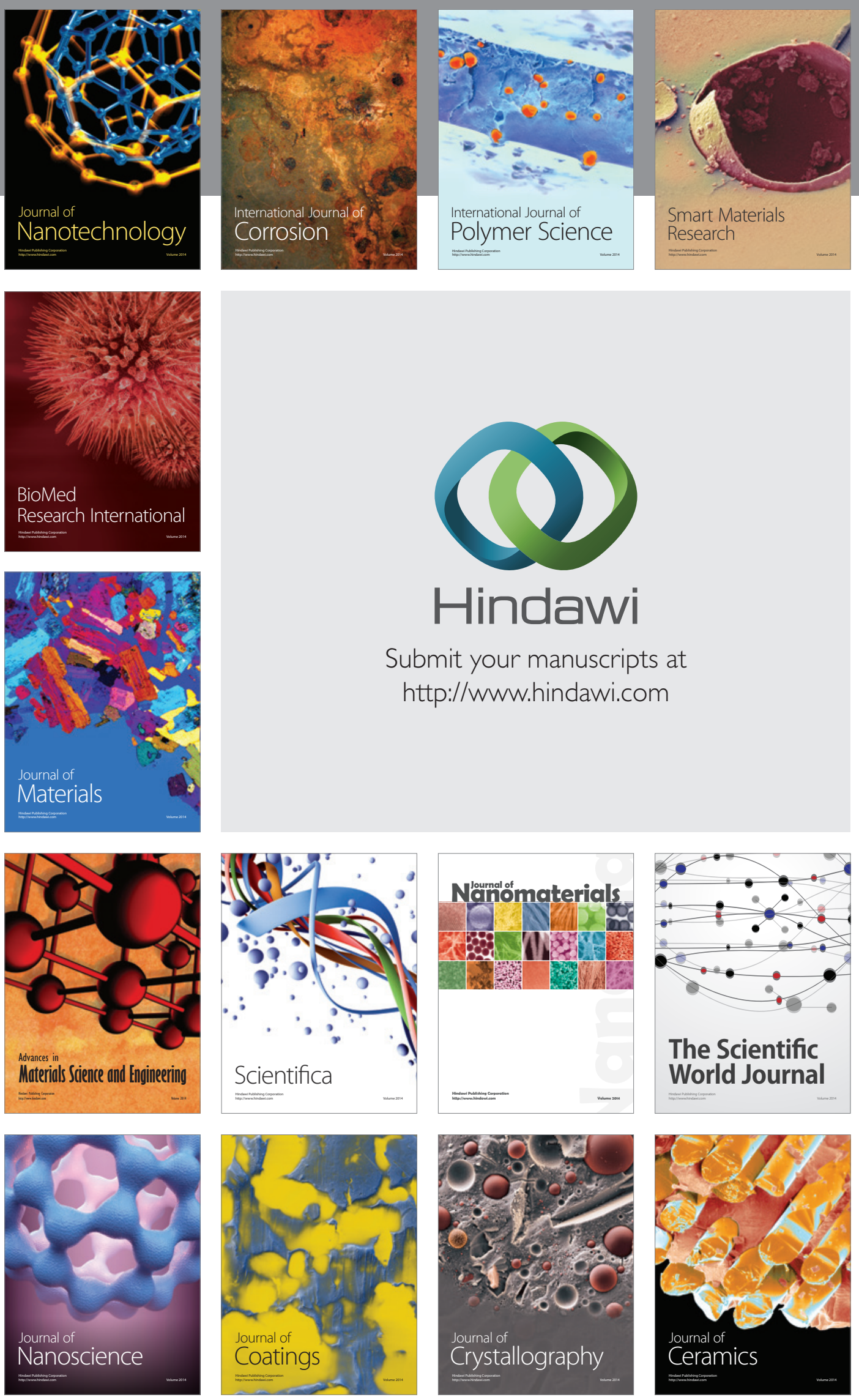

The Scientific World Journal

Submit your manuscripts at

http://www.hindawi.com

\section{World Journal}

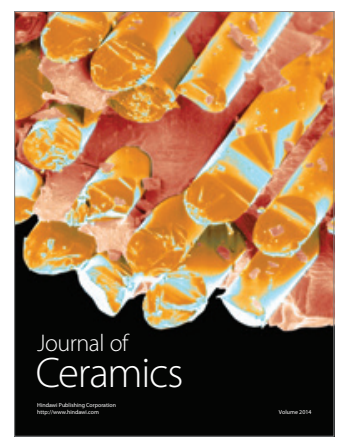

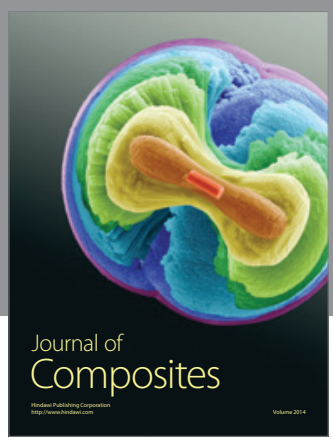
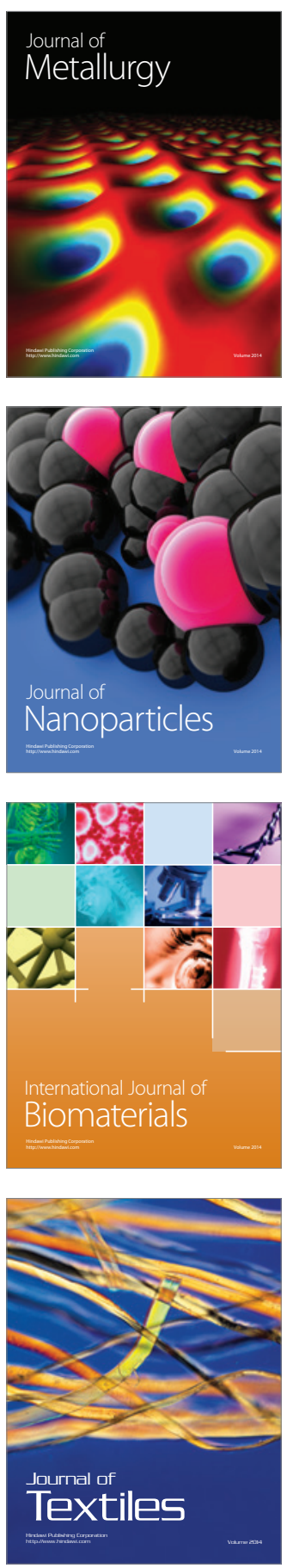